\title{
Explore the Medical Curriculum Teaching Development in the Smart Classroom
}

\author{
Yu Tai, Ying Wushuo, and Sha Kun
}

\begin{abstract}
Smart Classroom is a teaching space includes a variety of modern equipment establishments and advanced educational philosophy of teaching. In view of the complexity and the practice of medical curriculum teaching, the space structure of the smart classroom should provide remote interactive teaching, remote operation, classroom group discussion and showing, classroom HD recording, attendance voting and other functions, it will have a profound influence on Curriculum teaching. By clarifying the concept of classroom, clearing the particularity of medical teaching, exploring the smart classroom teaching and classroom space architecture how to carry out medical curriculum teaching, in order to provide reference for the application of smart classroom in medical colleges.
\end{abstract}

Index Terms - Smart classroom, medical curriculum teaching, curriculum interaction, new technology.

\section{INTRODUCTION}

With the Internet of things, cloud computing, big data as a representative of a new generation of information technology has become increasingly mature, in the field of education, smart classroom with the characteristics of intelligent technology, intelligent application, wisdom management has become the new information construction hotspot. The emergence of these new technologies will have a profound impact on our teaching environment, teaching mode, teaching content, evaluation mode and management mode and so on[1]. While in the process of students learning, classroom teaching is the most important part of students to acquire knowledge. Medical curriculum teaching emphasizes on the situation and cooperation, and emphasized the importance of the students' learning initiative and exploration ability. The emergence of smart classroom turn classroom learning environment into the high-tech content, which created the interactive classroom teaching efficiency for the teachers and students learning situation, promote the students' active learning and cooperative learning, and then improve the efficiency and results of the medicine curriculum teaching. The purpose of this paper is to expound the classroom wisdom, on the basis of definition and spatial structure, explore how to carry out medical wisdom in the classroom of the classroom teaching, thinking in the wisdom of the classroom to carry out medical teaching should focus on consideration of the difficulty in the process, in order to offer reference to the comprehensive

Manuscript received September 12, 2015; revised November 30, 2015.

Yu Tai and Sha Kun are the Second Military Medical University, China (The corresponding author: Sha Kun; e-mail: yutai87@163.com, kunie@smmu.edu.cn).

Ying Wushuo is with Shanghai University of Medical and Health Sciences, China (e-mail: yvette.87@ hotmail.com). application of the smart classroom in medical colleges and universities [2].

As "smarter Planet" (Smart Planet) concept is put forward, the application of intelligent technology, the smart of medical treatment, traffic, power, urban infrastructure and even smart city, education, campus, classroom arises at the historic moment. At present, the domestic scholars for "smart" of the classroom doesn't have a unified definition, and distinguish between the "intelligent classroom" and "smart classroom", "immersion classroom", "future class" and other concepts are not very clear. But it is clear that the smart classroom is based on humanism, constructivism and other learning theory, to use of such as Internet of things, cloud computing, sensor technology, artificial intelligence and other advanced technologies, to activation of teacher-student classroom interaction, seamless link extra-curricular resources, expand classroom space and time of intelligent new classroom environment[3]. The smart classroom as the basis of teaching, it should set the wisdom, the real-time interaction, environmental control, video monitoring and remote control, the educational reform the innovation, the evaluation of feedback, and other functions into an organic whole, give full play to the role of the various elements of the classroom ((human, technology, resources, environment and methods, etc.), realize the application of intelligent services, to achieve the best teaching effect.

\section{THE CHARACTERISTICS OF MEDICAL ClASSROOM TEACHING}

The integrity of the medical science, complexity, practicality and sociality determines the teaching of medical education is a huge system, It covers a wide range of information transmission media, such as text, images, forms, audio, video, etc., but the traditional classroom teaching methods often time-consuming, and difficult to achieve good results. Medical science has an extremely complex subject characteristics:

The particularity of research object. Such as protein biosynthesis process, the process of cell division, the formation and development of fetal dynamic change process, These abstract objects need to build three-dimensional concepts and abstract thinking ability to understand, If you just stay in the traditional blackboard, models, wall charts, and other presentation, without the aid of advanced technology description and presentation, are often unable to achieve the desired effect of teaching.

Medical terminology and more abstract and complex concepts, it is difficult to understand the memory, such as biochemistry course, multiple structured, metabolic pathways, 
many more abstruse content is deep and complex, in the traditional classroom teaching, the students often feel boring and difficult to lift interest in learning, it will affects learning effect[4].

Between the medical curriculums has a strong mutual interpenetration and permeability. As between medical microbiology and parasitological, biology, immunology, pathology, pharmacology, biochemistry, molecular biology, molecular genetics and many other disciplines have extensive and close contact. How to get through the barrier between the common courses, to achieve resource sharing, is the one of the difficulties in medical classroom teaching.

\section{TeChnology In Medical ClassRoom Teaching}

\section{A. Interactive Electronic Whiteboard}

Interactive electronic whiteboard is induced from the electronic induction board (hardware) integrated with the whiteboard operating system (software). It combines computer technology, sensing technology, positioning technology, microelectronics technology and electronic communications technology, has become a computer based on an input-output devices and sensors whiteboard, is people ( users ) to interact with the computer 's intelligence platform .Interactive electronic whiteboard is the product of information science and technology. As a new modern teaching tool, interactive electronic whiteboard advantage is able to effectively integrate various teaching resources, improve the utilization of teaching resources, has great effect to improve the classroom efficiency [5]. On the other hand, interactive electronic whiteboard system is composed of projector, computer and electronic whiteboard, this kind of teaching method has the characteristics of the content is rich and colorful, in the form of a variety of features, by the vast number of teachers and students like it, has been widely used in medical classroom teaching, and have achieved satisfactory results.

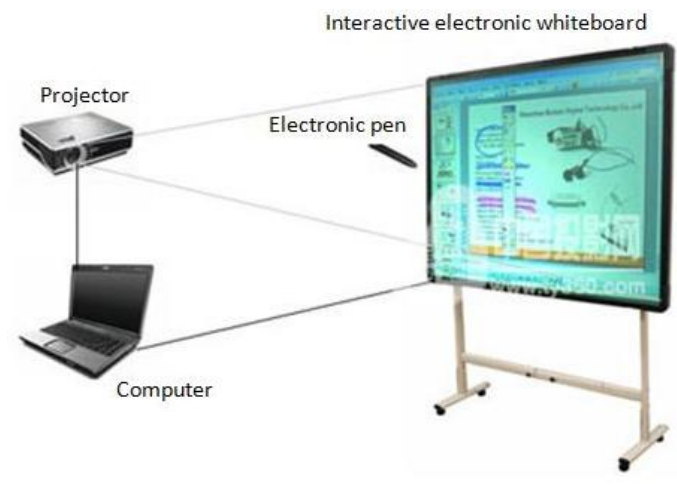

Fig. 1. Interactive electronic whiteboard system.

\section{B. Automatic Recording System}

Automatic recording system can be automatically generate live video classroom when the teachers are teaching at the same time, completely recorded the whole process of teachers' teaching, including teachers in the teaching process, and writing on the blackboard writing process and the use of multimedia courseware, etc., automatically editor and generated live teaching video according to the school time sequence. At the same time, also in a streaming mode on the Internet to watch live, so that the majority of students in the classroom scene such as face to face the same feeling, after class can also be online on-demand playback. By using full automatic recording system can share the excellent teaching resources of famous teachers on the Internet, is also teacher training, curriculum evaluation, teaching observation, level evaluation, resource sharing mentor, provides a convenient way for more recording work of excellent courses. Automatic recording system uses two modes (software mode and hardware mode ) to collect teacher courseware screen display ; or through the intelligence director system switches the students and teachers of the picture, in order to reflect the effect of the interaction between teachers and students in classroom teaching; the use of the live server, will be broadcast live classroom to other computers on the network[6].

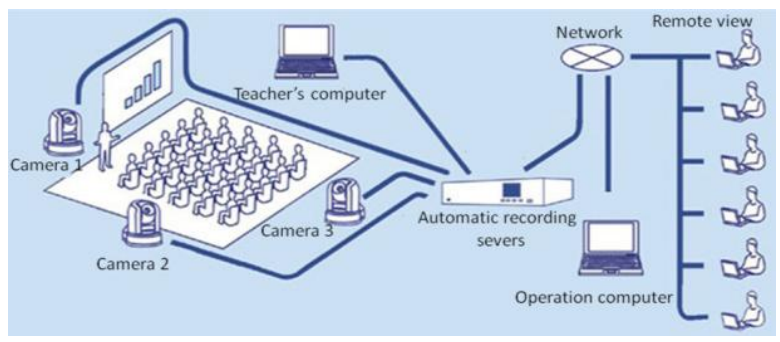

Fig. 2. The structure of automatic recording system.

\section{Interactive Response System}

Interactive Response System is through the electronic remote control, let the whole class of students in the classroom can be a real time feedback information to the teacher's teaching applications. IRS the most important function is to help the students to keep focus on classroom learning activities, and can motivate students' active learning. With the rapid development of information technology, the use of wireless electronic remote control allows IRS real-time feedback system to maximize performance, so that the teacher in the classroom teaching activity, at any time statistics student feedback and proportional, immediately grasp the learning situation of the whole class of students, and adjust the teaching steps.

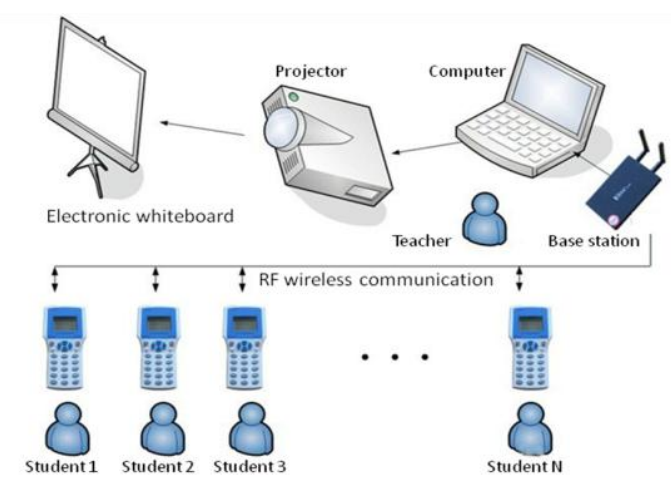

Fig. 3. The structure of interactive response system.

\section{Virtual Surgery}

With the rapid development of Internet and multimedia technology, virtual reality applied research has become one of the hot current computer research. In the field of education, 
virtual reality technology has extensive role and influence in it. In particular, we are concerned medical education, it requires a lot of experimental operation, distance medical education which based on virtual reality is very suitable for online virtual operating experiments, it provides a user immersion learning mode, the emphasis is through hands-on, problem-solving activities to achieve a series of self-study. The application of virtual reality technology in medical education, bring us new education thinking, to solve our previously unsolvable problems, bring a series of changes to our medical education. In a lot of technology of virtual reality, Virtual surgery assisted on classroom teaching is the most obvious. Virtual Surgery is the use of virtual reality technology, use of medical imaging data, to create a virtual environment in the computer. Students use the information in the virtual environment to surgery planning, drill, surgery teaching, skills training, guide the procedure during the operation, postoperative rehabilitation, etc [7]. This paper argues that the use of existing network technologies and tools, to develop a virtual network teaching platform, set up network surgical practice training platform, can from two aspects of "brain" and "hands-on" to cultivate medical students, improve the ability of clinical surgery and enable students into the real doctor role, better adapted to the clinical work.

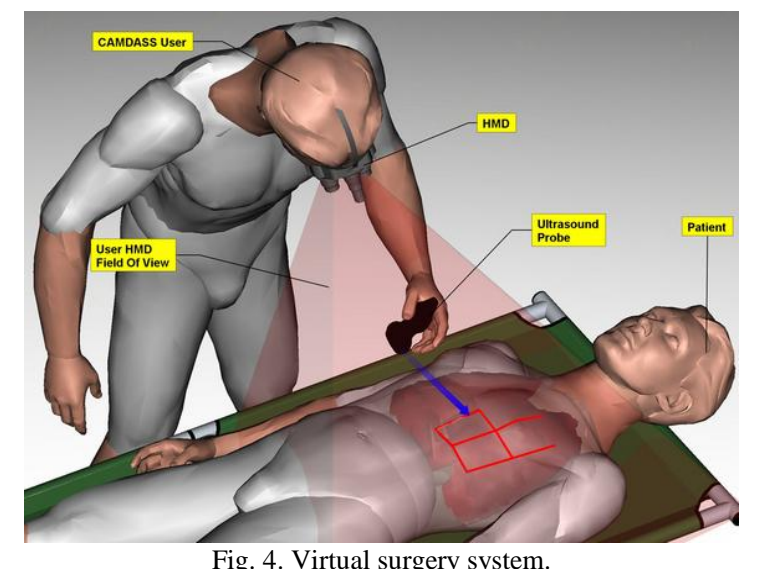

\section{The StRUCTURE OF SMART ClassRoOM}

In view of the particular requirements of medical teaching, the smart of the classroom space architecture should provide live remote interactive teaching, remote operation, class group discussions, group results show, the high-definition recording, class attendance voting and other functions, specifically to the space plan, mainly including the following five parts:

\section{A. Use Electronic Interaction Screen to Realize the Freedom of Interaction and Immersion Teaching between Teachers and Students}

At present, the vast majority of medical classroom teaching is based on the computer and projector multimedia demonstration system, the lack of flexibility and interactivity in the process of application, and the system can not meet the needs of teaching, students lack the opportunity to participate in classroom activities, then the learning effect is not good. The use of electronic interaction screen is very good to solve this problem. Interactive electronic whiteboard is a collection of traditional teaching wall charts, blackboards, computers, projectors, and other functions in one of the education information, both the dual advantages of multimedia teaching and the traditional blackboard. Teachers through the operation on the interactive electronic screen, can realize a flexible integration of a variety of resources, through creating a more than a screen display space for learning, for each team in the group discussion provide a display shared screen, promote cooperation group comparison and editing learning activities[8]. Such as the anatomy structure interpretation of the brain tissue term, the teacher can from the transfer of resources in the library on the brain of the flash animation or 3D virtual experiment, through the multi screen display, control text interpretation, mobilize the student or group in the interactive screen yourself manually drag and drop operation, three-dimensional rotation contrast, use visual thinking of ways to enhance students understanding on the concept, at the same time, the use of the interactive screen recording function of the classroom teachers and students on the whiteboard annotation and collection operations into a video file, showing the whole class the thread of thought, the formation of new teaching resources, for teachers and students after-school review and reflection. Such as the anatomy structure interpretation of the brain tissue term, teachers can obtain from the repository of flash animation or 3D virtual experiment, through the screen display, more contrast text explanation, students or group on the interaction screen manually drag and drop, three-dimensional rotation, use visual thinking ways to enhance students understanding of the concept, at the same time, using the interactive screen recording can be gather the teachers and students in the class notation on the whiteboard and acquisition for video file operation, rendering the whole class thinking, forming new teaching resources, for the use of teachers and students after class to review and reflection.

\section{B. Use High Definition TV and Large Mosaic Screen to Achieve Long-Distance Teaching Interaction and Remote Operation}

In the smart classroom to install high-definition TV, mosaic style big screen, and based on the Internet network, link to the smart classrooms in other universities or hospital surgery room, and to install the remote live interactive control equipment, screen switch control software alliance docking component, college courses, so it can realize remote interaction between teachers and students, multi-channel echo remote live broadcast, and other functions. In the process of remote teaching interaction, the TV can be real-time display other attended class scene or according to the teacher need to display own teaching scene to perfect the teaching process, when interaction between teachers and students in their own classroom, students can see their questioning on the mosaic scene; and when interacting with other classrooms, the students can see the computer screen in which other classrooms or students being asked in other classrooms. When carry out the remote operation, the students can understand the whole process of the operation, and the system can also provide the students' convenient, intuitive view, improve their understanding and memory ability, and improve the efficiency and effectiveness of medical skills training [9]. 


\section{Use HD Camera and Positioning Device to Achieve Synchronous HD Recording in Classroom Teaching}

In the smart classroom deployed automatic HD recording and broadcasting system, can greatly reduce the workload of manual recording, through the intelligent recording teaching process, automation of generative teaching resources, to achieve normalization of teaching application and value of teaching resources. Automatic HD recording and broadcasting system includes automatic operating platform, HD video camera, portrait locator, audio acquisition and noise reduction system, automatic recording and broadcasting editor, graphics and image workstation. Automatic recording and broadcasting system of intelligence is mainly reflected in a "multicar switching" director strategy, namely the use of installation in a classroom intelligent ultrasonic sensor placement of reservation switching technology. Through the scheduled strategy of intelligent platform for automatic recording and broadcast system, automatic switching teachers class recording scene, to realize automatic record the class, when teacher press the button on the computer, and use teaching computer mouse, keyboard, image, sound and other operation, the recording images automatically switch to the computer screen. When no more action, the recorded images automatically switch to the teachers. When the students have a speech, the recording scene will be automatically switched to the student scene; when the students do not speak, the recording scene will automatically switch to the teacher scene. If automatic recording and broadcasting strategy only control the recording scene, corresponding projection screen on the real-time teaching according to the courseware button switch.

\section{Use Splice Type of Desks and Chairs to Explore and Experiment of Various Teaching Modes}

Smart classroom is a decentralized classroom environment, classroom space is no longer a fixed cuboids, it can be in accordance with arbitrary shape of structural mechanics. The desks and chairs can be adjusted to users, classroom prominence to people's attention, to provide suitable for individual needs, accord with human body engineering lap-top, desks and chairs should be flexible, easy to move, and combination (e.g., can be designed into a trapezoid or hexagonal, triangular shape), the desks and chairs can according to the need of different teaching forms, for mosaic variegated and moderate scale of study groups. Medical teaching content is monotonous, and it lack of corresponding and practical operation, we must strengthen the medical knowledge and clinical practice, cultivate students' ability to analyze problems and solve problems, students and teachers in the smart classroom can be carried out PCMC (based on the clinical typical cases and problems as the forerunner of the heuristic) teaching, PBL (problem oriented) teaching, mixed teaching, etc., to fully mobilize students learning interest and learning enthusiasm, and use the smart classroom to show each team's discussion, the feedback from the teacher behavior, students get feedback in time, so as to enhance students learning effect.

\section{E. Use splice Type of Desks and Chairs to Explore and Experiment of Various Teaching Modes}

Use wireless network coverage to achieve information real-time transmission and collection. Learning environment in the classroom should be a simple, user-friendly, easy to use learning environment, and therefore in the environment of a large number of connections and communication between devices will need to use the wireless environment, including learning terminal - splicing big screen, learning terminal interactive display, learning terminal - Internet, etc., and also need to use cloud storage, real-time voting system and other network services. Wireless network supporting environment can realize the seamless connection between the majority of devices in the smart classroom learning environment, with the help of the movable tables and chairs, to better realize the interaction between the equipment, the teacher and the students, and to form an interactive and open learning environment. In the mobile learning terminal, whether it is tablet or mobile phone, both teachers and students can watch live broadcast on demand through wireless network, launch real-time polling questions, real-time sign in class, access to cloud resources, achieve high interactive, open, visualization of teaching and learning activities, teacher and research staff, school administrators can also access wireless network learning environment, to participate in the teaching process, to understand teaching progress.

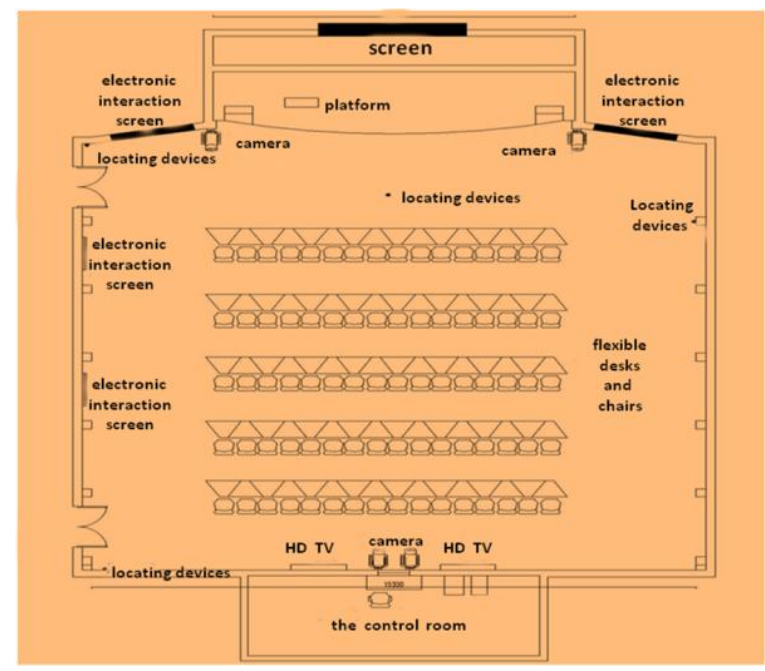

Fig. 5. The structure of smart classroom.

At the same time, the smart classroom under the support of the hardware environment to carry out, but also need the support from the platform and application software. To join the university curriculum alliance, can be based on the Internet to achieve the curriculum and resources sharing with the online interactive teaching; Construction of teaching video resources management center, providing video resources sharing, and the link between HD recording room and hospital surgical live room, to realize the automatic video recording and storage, supports fast retrieval and online live broadcast on demand; Construction of IRS real-time voting system, real-time feedback of students' voting results, monitoring the teaching effect; construction of the electronic book package system, support for the digital content of reading and presentation, to provide effective data support for teachers' teaching and students' learning; Construction of educational management system, supporting teaching data analysis management and online teaching evaluation, etc. [10]. Only in this integration of intelligent classroom environment, it is more conducive to the construction of individual learning 
environment, more conducive to the formation of social intercourse, freedom of the combination, freedom of interaction, free to show, so that the individual learning creativity, different groups of creative activities can effectively reflect.

\section{The Strategy of CARry OUt Medical CURriculum TEACHING IN SMART CLASSROOM}

As the most typical and the core of teaching environment, the classroom is increasingly from the stage of multimedia and network into the smart phase. The pursuit of smart in the classroom should not only limited to technical equipment and system composition, the more important is how to use the smart of the classroom to carry out medical classroom teaching activities, and promote medical teaching reform, so as to create a smart classroom. In the specific implementation process, we should focus on the following three aspects:

\section{A. The Change of Thinking}

Teachers should realize that the medical classroom teaching is actually an open and creative process. It should be treated with the whole and accepted viewpoint; Break through the shackles of the traditional education ideas, in the teaching process to guide students to explore the development, pay attention to the development of students' potential; Managers should be deeply sensed the impact of new technologies and new ideas to the classroom, the introduction of supporting policies and measures to encourage teachers, students, management personnel to use the smart classroom teaching in the teaching of new attempts, in the process of medical classroom teaching to achieve technology and discipline reasonable, timely and effective integration, and promote the full development of teaching.

\section{B. The Rich of Teaching Resources}

Teaching resources is one of the basic conditions for the development of the classroom, the quality of the resources directly affects the teaching effect, and even plays a decisive role. Modern equipment in the classroom can be used to present many forms and types of medical information resources, such as the use of text, images to present the basic concept and pathogenesis, the use of animation and sound to interpretation of the steps and mechanism changes; the use of video to presentation of teaching, clinical symptoms; the use of $3 \mathrm{D}$ model, flash animation to observe the human body, cell sections, etc..

\section{The Choice of Teaching Mode}

The traditional medical classroom teaching is the classroom and blackboard, lesson plans PPT, model chart, information representation way is single, less communication between teachers and students. The emergence of smart classroom for teachers and students to try a variety of teaching mode and teaching methods, such as case group discussion teaching, PCMC teaching, PBL (problem oriented) teaching, mixed teaching and so on. In the teaching process, how to choose appropriate teaching model to present medical information, how to realize the seamless connection between teaching content and teaching video, and how to avoid the bad tendency of "computer replace the human brain", it is all teachers and class leaders should consider problem.

Medical teaching methods from the traditional teaching to the multimedia teaching is a leap, we believe that from the plane of the multimedia teaching to multi screen display, remote interactive, operating live, immersed in the smart classroom teaching will be another major breakthrough. This breakthrough is not only across a technical limitations, and thorough breakthrough for medical students to understand learning barrier, it is not just a visual sense of change, but also a revolution of learning, will push the innovation and development of medical teaching.

\section{REFERENCES}

[1] Y.-J. Li and X. Yang, "Research on the application of interactive whiteboard in human anatomy course in medical university, Jilin," Medicine and Society, vol. 12, pp. 88-90, July 2013.

[2] J.-X. Li, Z.-J. Wang, and G.-B. Li, "The methods and problems of blackboard writing in medical classes," Chinese Journal of Medical Writing, vol. 2, pp. 56-56, May 1996.

[3] Y.-M. Zhu, "Construction of new medical teaching mode with modern educational technology," Human Resource Management, vol. 3, pp. 129-130, July 2009

[4] Y.-B. Zhang, "Study on the interaction in classroom teaching interactive whiteboard supported," China Information Technology Education, vol. 14, p. 26, 2014.

[5] J.-G. Ma, "The use of interactive electronic whiteboard activation information technology classroom," The Road to Success, vol. 24, p. 93, Jan. 2014

[6] H.-Y. Li and L. Zhong, "Characteristics and prospect of automatic recording system," China Education Info, vol. 5, pp. 84-86, June 2013.

[7] T.-L. Feng, L. Chen, H.-C. Chen, and L. Wang, "Design and Realization of multi-channel operation technology of stream media live broadcast teaching platform based on," Chinese Medicine Digital Magazine, vol. 4, pp. 66-69, Agu. 2009.

[8] Y. Lan, "Discussion on basic medical teaching method," Science and Technology Innovation Herald, vol. 26, p. 162, Oct. 2013.

[9] X.-H. Zeng and Z.-Q. Ji, "Research on the differences between Chinese and American higher education and experience in medical classroom on the culture," Anatomy Research, vol. 6, pp. 464-468, Sep 2012.

[10] J. Xin, "Application of multimedia courseware in classroom teaching in medicine," Journal of Datong Medical College, vol. 2, p. 56, July 2004.

Yu Tai was born in Sep. 1987. Yu Tai graduated from the Department of Educational Technology in East China Normal University, Shanghai, China, in 2010. Yu Tai's major field is educational technology and smart classroom.

Ying Wushuo was born in August 1984. Ying Wushuo graduated from the Department of Education in Shanghai Normal University, Shanghai, China, in 2011. Ying Wushuo's major field is higher vocational education and smart classroom. Sha Kun, Shandong people, was born on May, 1977. Sha Kun graduated from Second Military Medical University, Shanghai, China. Sha Kun's major field is campus informational construction and smart classroom. 